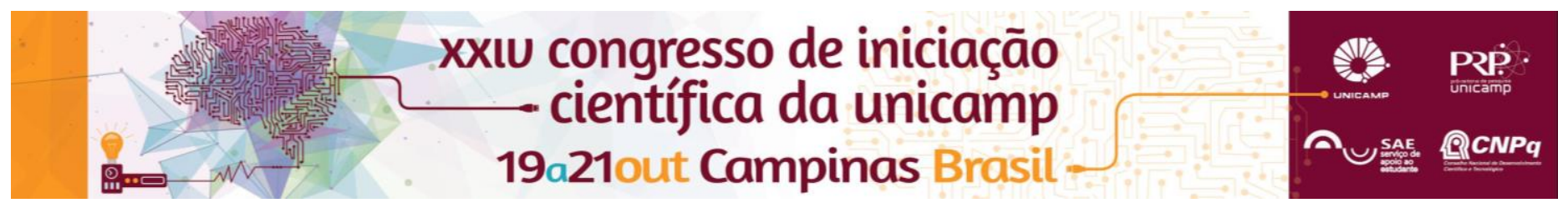

\title{
Sistemática do gênero Polymerurus (Gastrotricha: Chaetonotidae) no Brasil
}

\section{André R. S. Garraffoni, Letícia M.M. Estevão}

\section{Resumo}

Este trabalho visa identificar a diversidade do gênero Polymerurus no Brasil a partir de caracteres morfológicos e moleculares de espécimes coletados em diferentes regiões brasileiras. Variações nas características morfológicas observadas para cada região sugerem a existência de dois morfotipos até o momento. Na sequência, será analisada a diversidade genética para o reconhecimento de táxons existentes e descrição de novos táxons encontrados.

\section{Palavras-chave}

Gastrotricha, Polymerurus, diversidade.

\section{Introdução}

O filo Gastrotricha é um grupo diverso formado por microinvertebrados tipicamente meiobentônicos. O gênero Polymerurus Remane, 1927 inclui 19 espécies e os maiores representantes da família Chaetonotidae (260-770 $\mu \mathrm{m}$ de comprimento), caracterizados por um corpo alongado e furca longa e segmentada (fig1). Contando com duas espécies cosmopolitas e diversidade pouco descrita, são necessários estudos mais aprofundados sobre esse grupo.

Assim, nosso objetivo é identificar e descrever a diversidade do gênero Polymerurus no Brasil, relacionando os táxons encontrados em cada região. Com isso, buscamos expandir o conhecimento a respeito desse grupo, possibilitando a elaboração de novas hipóteses sistemáticas e evolutivas.

\section{Resultados e Discussão}

Os espécimes foram coletados em Paulínia, Broa (SP), Diamantina, Soberbo (MG), Cáceres (MT) e Fernando de Noronha (PE) e fotografados, utilizando microscopia ótica e eletrônica. A descrição comparativa das características morfológicas observadas permitiu distinguir, até 0 momento, dois morfotipos: um apresentando escamas ovais pedunculadas sem espinhos, encontrado em Paulínia, Diamantina e Soberbo, e outro com escamas que portam espinhos, coletado em Fernando de Noronha, Cáceres, Broa e Paulínia. Registramos variações morfológicas entre espécimes, principalmente nas dimensões gerais e na cobertura corporal de escamas e espinhos (fig.2). Um par de espinhos curtos posteriores (fig.3) é compartilhado por espécimes de 5 dos 6 locais.

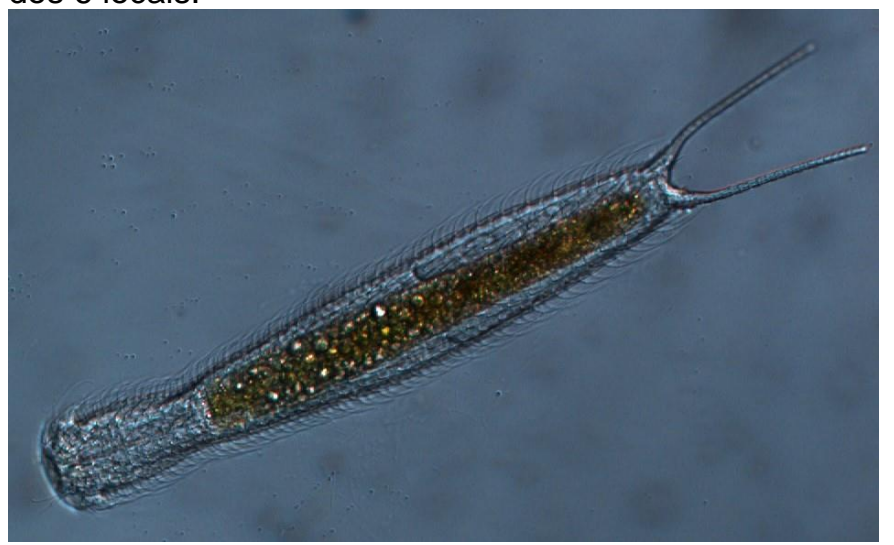

Figura 1. Espécime coletado em Paulínia Com base nesses resultados, identificaremos os possíveis táxons presentes em cada área de coleta e, a partir deles, faremos um levantamento da diversidade entre as regiões.

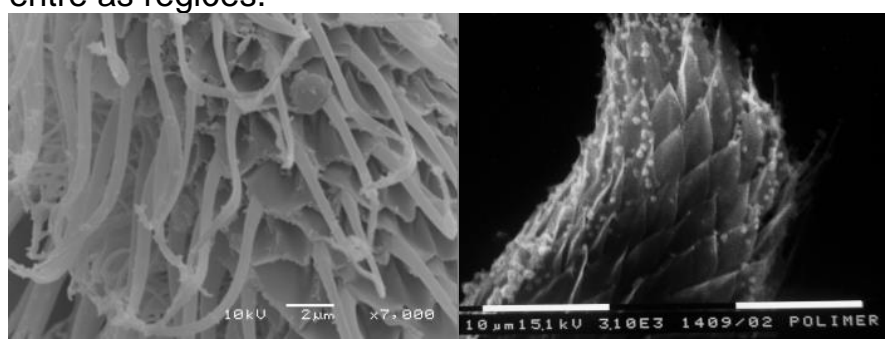

Figura 2. Exemplos dos dois morfotipos de Fernando de Noronha e Diamantina: diferentes espinhos e escamas.

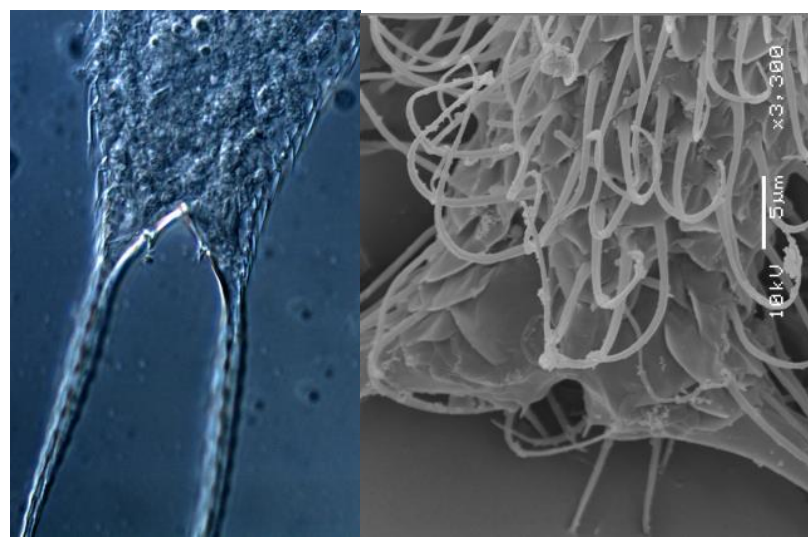

Figura 3. Par de espinhos compartilhado

\section{Conclusões}

A diversidade de características morfológicas entre os espécimes coletados pode sugerir a existência de diferentes táxons nas áreas estudadas. Para complementar os resultados obtidos, será feito um conjunto de análises moleculares. Maiores investigações permitirão identificar esses táxons e compreender suas relações filogenéticas, bem como sua diversificação no território brasileiro.

\section{Agradecimentos}

À PRP-FAEPEX, pela bolsa de iniciação científica.

Aos colegas de laboratório, pela realização das coletas. 